\title{
Urban distribution of Phlebotominae in a cutaneous leishmaniasis focus, Argentina
}

\author{
Oscar D Salomón/ ${ }^{+}$, María G Quintana', Mario Zaidenberg² \\ Centro Nacional de Diagnóstico e Investigación en Endemo-Epidemias, CENDIES-ANLIS, Av. Paseo Colón 568, 1063 Buenos Aires, \\ Argentina ${ }^{1}$ Instituto Superior de Entomología Dr Abraham Willink, Universidad Nacional de Tucumán, Argentina ${ }^{2}$ Coordinación \\ Nacional de Vectores, Delegación Salta, Argentina
}

Urbanization and vector domestication are currently proposed as factors that contributed to the recent increase of American cutaneous leishmaniasis (ACL). Is likely also urban transmission? Oran is the main city in the Argentinean hyper-endemic area of ACL, and human cases in urban residences are usually reported. In order to assess the spatial distribution of risk, phlebotomine traps were located in different environments of Oran. A total of 7,787 sand flies were captured: Lutzomyia neivai (98.1\%), Lutzomyia migonei (1.2\%), Lutzomyia cortelezzii $(0.7 \%)$, and one Lutzomyia shannoni. During the season of transmission (April-May) a single sand fly was obtained in one out of five urban sites, while a trap in a peri-urban pigsty captured up to 2,985 Lu. neivai/night. Captures performed in the other season of vector activity (September-October) revealed that small-scale changes in the pigsty environment resulted in noticeable changes in the abundance of Lu. neivai. In addition, in a new neighbourhood, on the fringe of the city, 1,073 Lu. neivai/ site were captured in the forested edge but one in the yard of the houses. Therefore, in this urban ACL focus the humanvector effective contact risk is still associated with peri-urban vegetation and ecotone modifications despite the urban residence of the cases.

Key words: cutaneous leishmaniasis - Lutzomyia neivai - urbanization - Argentina

The number of cases of cutaneous leishmaniases increased in the last decades worldwide, in almost all the endemic countries. Urbanization, landscape modification, peridomestic transmission, and vector domestication were frequently proposed as factors that contributed to this emergence, mainly in the Americas (Mott et al. 1990, Campbell-Lendrum et al. 2001, Desjeux 2001, Bejarano et al. 2002, Rangel \& Lainson 2003, Leonardo \& Rebêlo 2004, Lemos \& Lima 2005, Shaw 2007). These factors also arise the probability of urban transmission.

In Argentina, the American cutaneous leishmaniasis (ACL) incidence from 1954 to 1983 was 2.93 cases/ year/10 6 inhabitants, but from 1984 to 2005 it rose to 8.76 cases/year $/ 10^{6}$ inhabitants. ACL is endemic through a wide region above $29^{\circ} \mathrm{S}$, however Oran and San Martin departments in the province of Salta reported $53.1 \%$ of all cases, although only $0.7 \%$ of the country's population lives there (SINAVE-Ministry of Health, INDEC-Ministry of Economy databases). This hyper-endemic area had $66.4 \%$ of the ACL cases already in 1930 (Bernasconi 1930), but also recorded the first epidemic outbreak of ACL in Argentina during 1984-1985 (Sosa-Estani et al. 2000), and the largest outbreak ever observed in the country with more than 900 clustered cases in 1998

Financial support: Pan-American Health Organization - Small Grants Program for Operational Research on Tropical Diseases, ANPCyT BID 1201/OC-AR-PICT R n. 275

OD Salomón and MG Quintana are members of Conicet.

+ Corresponding author: odanielsalomon@gmail.com

Received 9 January 2008

Accepted 11 April 2008
(Salomón et al. 2001). Leishmania (Viannia) braziliensis was isolated from human cases during the outbreaks (Segura et al. 2000, Cordoba-Lanus et al. 2005), and Lutzomyia neivai was incriminated as its main vector (Cordoba-Lanus et al. 2006). The prevalence and distribution of $L u$. neivai along with the recent increase in female and child ACL incidence, contributed to the hypothesis of peridomestic transmission (Sosa-Estani \& Salomon 2002). Landscape modifications along with peridomestic transmission and vector domestication were proposed to contribute to the epidemic outbreaks reported since 1985 in Argentina (Salomon et al. 2006).

Oran city with 66,500 inhabitants is the main city in the ACL hyper-endemic area of Argentina. Human ACL cases in urban residences of Oran are usually reported both during epidemic outbreaks and inter-epidemic periods. The perception of urban transmission is shared among the community, primary health care agents and physicians. Therefore, Lutzomyia captures were performed in the city and its outskirts, during the two annual phlebotomine peaks (fall and spring), in order to assess the relative abundance of sand flies in different habitats, as an indicator of the spatial distribution of human-vector contact probability during inter-epidemic periods. The results will contribute to the current discussion of the ACL urbanization process, and for developing appropriate control strategies with an adequate spatial allocation of resources.

\section{MATERIALS AND METHODS}

Oran city (San Ramon de la Nueva Oran) is located at $23^{\circ} 08^{\prime} \mathrm{S} 64^{\circ} 20^{\prime} \mathrm{W}, 270 \mathrm{~km}$ Northeast of Salta city and $46 \mathrm{~km}$ South from the border with Bolivia. This area of the Andean foothills is classified as subtropical humid 
forest. It has grading to xeric forests in the West (Cabrera 1971) and is mostly modified close to the city. Adult phlebotomine sand flies were captured with CDC light traps (Sudia \& Chamberlain 1962) that were simultaneously placed in 11 georeferenced sites of Oran (Fig. 1) on three consecutive nights, from April 27th to April 29th, 2004. The traps were placed $1.5 \mathrm{~m}$ above the ground, the devices operated from 19:00 $\mathrm{h}$ to 9:00 $\mathrm{h}$. Peridomestic sites were selected surrounding the city border, in areas with transitional rural-urban habitats covered with vegetation and inside the city in places related to past cases or parks. Captures with the same methodology were performed on five consecutive nights from May 2 nd to 6 th in ten sites up to $210 \mathrm{~m}$ from site A1 (Fig. 2). The sites surrounding the city and several sites close to site $\mathrm{L}$ were sampled again on two consecutive nights from September 29th to October 3rd 2005 (Fig. 3). The landscape of the capture sites are detailed in the results. All captured sand flies were stored dry until the identification was made according to Young and Duncan (1994) and Marcondes (1996). Fisher and $\chi^{2}$ tests were used for bivariate analysis. All statistical tests were considered significant at $p<0.05$. Sex ratios (female:male) were computed only when the total capture had more than 15 individuals. Gravid females were quantified as a percentage of the total females of each species, and the proportions were computed only when the amount of females captured was more than 15. The satellite images Landsat 7 ETM path/ row 231/76 and 231/75, date 16th June 2004, bands 347 were provided by CONAE (Comisión Nacional de Actividades Espaciales). The weather data were provided by the National Metereological Service, Oran station.

\section{RESULTS}

A total of 7,787 sand flies were captured in Oran city and surrounding areas. Lu. neivai was the most prevalent species with 7,637 sand flies (98.1\%), followed by
93 Lutzomyia migonei (1.2\%), 56 Lutzomyia cortelezzii (0.7\%), and a single Lutzomyia shannoni male (Nyssomyia neivai, Migonemyia migonei, Evandromyia cortelezzii, Psathyromyia shannoni according to Galati 2003). The sex ratios were 1.5, 0.6 and 1.8 for the former three species respectively.

Simultaneous captures in April 2004, during the high transmission season, at 11 different sites showed that phlebotomine abundance was associated with two areas on the border of the city (Table I, Fig. 1). The most important site was in the peri-urban vegetation of the Southern corner (site A1) extending to the West side (B,C1-C2) and South side (I). Some individuals were also captured in the Northern area $(\mathrm{E}, \mathrm{K})$ in more modified environments, even in the backyard of an urban house. No sand flies were captured in the other sites, despite recent ACL cases $(\mathrm{H}, \mathrm{G})$, and deforestation (D), or in urban green patches $(\mathrm{F}, \mathrm{J})$.

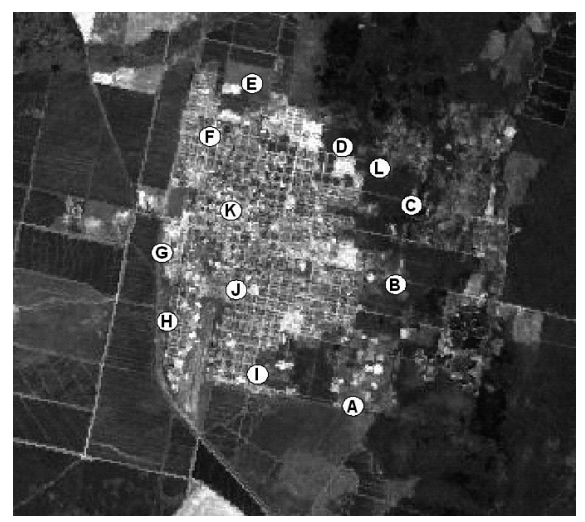

Fig. 1: phlebotomine capture sites. San Ramón de la Nueva Orán, Salta, Argentina, April-May 2004 (Image Source: Landsat 7 TM, path/row 231/76, bands 347, 07/29/02, provided by CONAE).

TABLE I

Phlebotomine/trap/night captured by sites and species, San Ramón de la Nueva Orán, Salta, Argentina, 27th to 29th April 2004 (rows 1-8), and 29th September to 3rd October 2005 (rows 9-14)

\begin{tabular}{|c|c|c|c|c|c|c|c|}
\hline Capture & Site & Lutzomyia neivai & $\mathrm{F}: \mathrm{M}$ & $\mathrm{GF} \%$ & Lutzomyia migonei & Lutzomyia cortelezzii & Total \\
\hline \multirow[t]{8}{*}{2004} & $\mathrm{~A} 1^{a}$ & $110.0^{d}$ & $2.5^{d}$ & $2.5^{f}$ & 0.7 & 0.0 & $332^{h}$ \\
\hline & $\mathrm{B}^{a}$ & 21.0 & 3.2 & 10.4 & 0.0 & 0.0 & 63 \\
\hline & $\mathrm{C} 1^{a}$ & $8.3^{e}$ & $11.5^{e}$ & $60.9^{g}$ & 0.7 & 0.0 & $27^{i}$ \\
\hline & $\mathrm{C} 2^{a}$ & $8.3^{e}$ & $5.2^{e}$ & $57.1^{g}$ & 0.7 & 0.0 & $27^{i}$ \\
\hline & $\mathrm{E}^{a}$ & 0.7 & na & na & 0.0 & 0.0 & 2 \\
\hline & $\mathrm{I}^{a}$ & 4.0 & na & na & 2.7 & 1.0 & 23 \\
\hline & $\mathrm{K}^{a}$ & 0.7 & na & na & 0.0 & 0.0 & 2 \\
\hline & $\mathrm{D}, \mathrm{F}, \mathrm{G}, \mathrm{H}, \mathrm{J}^{a}$ & 0.0 & na & na & 0.0 & 0.0 & 0 \\
\hline \multirow[t]{6}{*}{2005} & $\mathrm{~A} 1^{b}$ & 1.0 & na & na & 1.0 & 0.5 & 5 \\
\hline & $\mathrm{A} 2^{b}$ & 7.5 & 2.3 & 0.0 & 2.0 & 2.0 & 23 \\
\hline & $\mathrm{C} 1^{b}$ & 22.0 & 1.0 & 0.0 & 7.5 & 3.5 & 66 \\
\hline & $\mathrm{C} 2^{b}$ & 3.5 & na & na & 1.5 & 4.0 & 18 \\
\hline & $\mathrm{L}^{b}$ & 295.5 & 1.1 & 21.6 & 1.0 & 3.5 & 600 \\
\hline & $\mathrm{K}^{c}$ & 2.0 & na & na & 0.0 & 0.0 & 2 \\
\hline
\end{tabular}

F:M: Lu. neivai female/male ratio; GF\%: Lu. neivai proportion of gravid females; na: less than 15 individuals; a: three nights of captures; $b$ : two nights; $c$ : one night; $a, b, c, d, e, f, g, h, i$ : each letter differed significantly from the other with a $p<0.05$. Sites are as listed in Fig. 1 . 
The trap site A1 was located below the roof of an animal dwelling with more than 20 pigs in a peri-urban farm. The trap site B was at a smaller farm with only two pigs and chickens. Trap sites $\mathrm{C} 1$ and $\mathrm{C} 2$ were located within secondary vegetation, separated $200 \mathrm{~m}$ from each other, near an artificial water reservoir. Site A1 and sites C1-2 showed significant differences between the total abundance, proportion of gravid females, sex ratios (Table I), and relative proportion of $L u$. migonei (0.9\%-7.0\%). The capture at site B was intermediate between those at sites A and $\mathrm{C}$, although $\mathrm{Lu}$. migonei were not captured at this site. On the other hand, site I showed the highest relative abundance of Lu. migonei $34.8 \%$ and Lu. cortelezzii $13.0 \%$.

Several places around site A1 were surveyed with nine traps afterwards in order to determine the sand fly micro-scale distribution (Table II, Fig. 2). The highest number of captures was still found inside the pigsty, followed by bamboo cane patches at $15 \mathrm{~m}$ and $25 \mathrm{~m}$ from A1, the unroofed corner of the dwelling, the residual vegetation, and a fence of banana trees. The other sampling sites produced scarce individuals of two out of the three species. The gravid female proportion varied significantly from place to place while the sex ratio remained similar. Aside from the spatial abundance heterogeneity there was a significant difference $(\mathrm{p}<0.05)$ between days due to weather variations (Table II).

A new neighbourhood was built in the Oran fringe during 2004-2005, after the captures detailed above, so the trapping was performed in control and the new sites during the following season of sand fly activity, in September-October 2005 (Table I). Unfortunately the effort was slightly different between years ( 3 to 2 nights/ trap) due to the weather conditions. Sites A1, A2, and C2 had a lower abundance of $L u$. neivai and a higher relative abundance of the other species than in June 2004. The urban site $\mathrm{K}$ yielded a scarce amount of sand flies and the



Fig. 2: capture sites inside a peri-urban farm. Site A1 is the same as that shown in Fig. 1. Distances from site A1 are listed. San Ramon de la Nueva Oran, Salta, Argentina, May 2004.

newly sampled site $\mathrm{L}$ had the highest capture rate of $L u$. neivai. The results of the traps located around site $\mathrm{L}$ in 2005 showed again an association between the density of vegetation and the abundance of phlebotomine at the border of the recently settled neighbourhood (Table III, Fig. 3).

\section{DISCUSSION}

The captures made in Oran city in late April, during the high ACL transmission season (Salomon et al. 2004), showed a 'hot spot' distribution of phlebotomine in the city outskirts, but very scarce individuals were present

TABLE II

Lutzomyia neivai (female/male) captured in the sites surrounding the pig pen (site A1) by night and site. San Ramón de la Nueva Orán, Salta, Argentina, from 2nd to 6th May 2004

\begin{tabular}{lccccccccc}
\hline Site & $6 / 2$ & $6 / 3$ & $6 / 4$ & $6 / 5$ & $6 / 6$ & Lu. neivai & F:M & GF\% & $\begin{array}{c}\text { Total of others sand } \\
\text { flics species }\end{array}$ \\
\hline A1 & $1901 / 1084$ & $87 / 54$ & $1 / 0$ & $6 / 10$ & $74 / 18$ & $2069 / 1166$ & 1.8 & $0.9^{a}$ & $6 / 2$ \\
A2 & $232 / 237$ & $32 / 31$ & $0 / 0$ & $1 / 2$ & $6 / 3$ & $271 / 273$ & 1.0 & $3.0^{b}$ & $1 / 0$ \\
A3 & $293 / 146$ & $81 / 157$ & $0 / 0$ & $7 / 4$ & $33 / 12$ & $414 / 319$ & 1.3 & $2.7^{b}$ & $10 / 12$ \\
A4 & $164 / 113$ & $35 / 53$ & $0 / 0$ & $4 / 2$ & $12 / 8$ & $215 / 176$ & 1.2 & $5.6^{c}$ & $5 / 6$ \\
A5 & $23 / 16$ & $0 / 1$ & $0 / 0$ & $1 / 1$ & $1 / 2$ & $25 / 20$ & 1.2 & $12.0^{d}$ & $1 / 2$ \\
A6 & $35 / 39$ & $5 / 4$ & $0 / 0$ & 0 & $2 / 0$ & $42 / 43$ & 1.0 & $0^{e}$ & $2 / 3$ \\
A7 & $13 / 6$ & $2 / 2$ & $0 / 0$ & 0 & $0 / 1$ & $15 / 9$ & 1.7 & $13.3^{d}$ & $1 / 1$ \\
A8 & $2 / 2$ & 0 & $0 / 0$ & 0 & 0 & $2 / 2$ & na & na & $0 / 0$ \\
A9 & $1 / 1$ & $3 / 0$ & $0 / 0$ & $1 / 1$ & $1 / 1$ & $6 / 3$ & na & na & $0 / 0$ \\
A10 & $25 / 38$ & $22 / 27$ & $0 / 0$ & $1 / 2$ & $33 / 12$ & $81 / 79$ & 1.0 & $17.3^{f}$ & $1 / 0$ \\
\hline Rain & $0.0^{g}$ & $0.2^{h}$ & $3.0^{g}$ & $1.0^{g}$ & $0^{g}$ & & & & \\
max T & 26.5 & 20.8 & 12.6 & 15.6 & 18.0 & & & & \\
min T & 17.3 & 18.8 & 11.7 & 10.7 & 12.0 & & &
\end{tabular}

F:M: Lu. neivai female/male ratio; GF\%: Lu. neivai proportion of gravid females; Rain: cumulative rain (mm); max T: maximal temperature $\left(\mathrm{C}^{o}\right)$; min T: minimal temperature $\left(\mathrm{C}^{\circ}\right)$; na: less than 15 individuals; $a, b, c, d, e, f$ : each letter differed significantly from the other with a $<0.05$; $g$ : without rain during the night; $h$ : drizzles during the night. Sites are listed as in Fig. 2. 
TABLE III

Lutzomyia neivai (female/male) captured in the sites surrounding the banana trees patch (site L1) by night and site. San Ramón de la Nueva Orán, Salta, Argentina, from 29th September to 3rd October 2005

\begin{tabular}{|c|c|c|c|c|c|c|c|c|}
\hline Site & $29 / 9$ & $30 / 9$ & $1 / 10$ & $3 / 10$ & $\begin{array}{c}\text { Total } \\
\text { Lu. neivai }\end{array}$ & $\mathrm{F}: \mathrm{M}$ & $\mathrm{GF} \%$ & $\begin{array}{l}\text { Total of others sand } \\
\text { flics species }\end{array}$ \\
\hline L1 & $250 / 240$ & $55 / 46$ & - & $296 / 186$ & $601 / 472$ & 1.3 & 12.3 & $5 / 6$ \\
\hline L2 & $238 / 66$ & $36 / 23$ & $38 / 29$ & $154 / 85$ & $466 / 203$ & 2.3 & 13.1 & $7 / 8$ \\
\hline L3 & - & - & - & $2 / 0$ & $2 / 0$ & na & na & $1 / 0$ \\
\hline L4 & - & $3 / 13$ & - & $2 / 0$ & $5 / 13$ & na & na & $0 / 0$ \\
\hline L5 & - & - & - & $1 / 0$ & $1 / 0$ & na & na & $1 / 0$ \\
\hline Rain & 0 & 0 & 0 & 0 & 0 & 0 & 0 & 0 \\
\hline $\max \mathrm{T}$ & 34.0 & 26.7 & 29.5 & 35.6 & & & & \\
\hline $\min \mathrm{T}$ & 16.1 & 10.0 & 10.4 & 16.9 & & & & \\
\hline
\end{tabular}

F:M: Lu. neivai female/male ratio; GF\%: Lu. neivai proportion of gravid females; Rain: cumulative rain (mm); max T: maximal temperature $\left(\mathrm{C}^{\mathrm{o}}\right)$; min T: minimal temperature $\left(\mathrm{C}^{\mathrm{o}}\right)$; na: less than 15 individuals. Sites are listed as in Fig. 3.

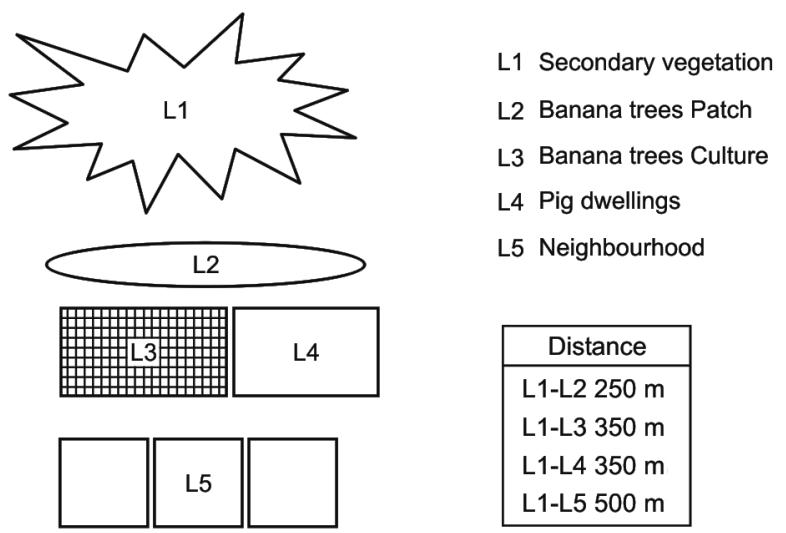

Fig. 3: capture was close to La Florida neighbourhood. Site L1 is the same as that shown in Fig. 1. Distances from site L1 are listed. San Ramon de la Nueva Oran, Salta, Argentina, September-October 2005.

in only one out of five 'inner city' places. Therefore, in this urban ACL focus the human-vector effective contact risk is still associated with peri-urban vegetation and ecotone modifications despite the urban residence of the cases.

The Southeast angle with dense vegetation coverage in the rural-urban interface had the largest captures of $L u$. neivai and $\mathrm{Lu}$. migonei, species incriminated as vectors of ACL (Rangel \& Lainson 2003). Further, in an ACL focus of Rio de Janeiro, Brazil, L. (V.) braziliensis was found by PCR multiplex both in Lutzomyia intermedia (sibling species of Lu. neivai) and Lu. migonei (de PitaPereira et al. 2005). During 1998 an ACL outbreak took place among children from an elementary school contiguous to site A10 (L Canini unpublished observation).

The peri-urban sand fly abundance is also highly heterogeneous according to the landscape. Site A is the pigsty of a farm with intense human activity, while site $\mathrm{C}$ is located within bushes visited by cows and wild rodents. These sites had different sand fly abundances, proportions of gravid females, sex ratios, and proportions of $\mathrm{Lu}$. migonei. The differences are consistent with an unstable and concentrated feeding source in site A and a disperse feeding source in site $\mathrm{C}$, which is inside a steady but shadowy ecotone and may be a potential breeding site (Wassemberg et al. 2003, Massafera et al. 2005). Site I, with the highest proportion of $\mathrm{Lu}$. migonei and $\mathrm{Lu}$. cortelezzii $(13.0 \%)$, is located in a peri-urban, peridomestic environment where many different botanical species alternate with cages of wild birds and mammals which generates a great diversity of microhabitats. Lu. migonei is a more eclectic sand fly (Rangel \& Lainson 2003), frequently associated with domestic animals in Argentina, that could be involved in the link between the zoonotic-anthropozoonotic transmission cycles (Chaves \& Añez 2004).

The captures performed in different sites around the pigsty showed also differences between each other, even in places separated by $15 \mathrm{~m}$. Aside from spatial variation, there are also daily changes in abundance due to weather variables, which may generate outbursts of vector abundance and so of potential vector-human contacts. The sand fly relative abundance in the pigsty/bamboo cane patch varied from 8.4 during a hot night to 0.6 in a cooler and drizzly night, suggesting that canes may provide rest stations on the way to and from the blood source. The phlebotomine abundance seemed to be more weather sensitive in peridomestic habitats than in the secondary vegetation patches. Thus, the time and space heterogeneity in the small scale confirms that selection of a trapping site that is representative of actual risk for surveillance purposes requires that the area be previously screened and sampled on several consecutive days (Alexander 2000). In this sense, the trap located close to the house indicated that this type of site is a bad indicator of risk because people often perform their evening and dawn chores outside of the house, during the peak activity of sand flies (Davies et al. 2000).

In order to assess the impact of the city growing toward the Northeast edge secondary forest, phlebotomine captures were performed again during SeptemberOctober 2005. The higher abundance of species other than $L u$. neivai in the beginning of the spring than in autumn was already reported (Salomon et al. 2004). The 'inner city' sites provided again very scarce amounts of vectors. Small-scale changes in the Southeastern border resulted in noticeable changes in $L u$. neivai relative abundance. The site $\mathrm{C} 1$ captures were consistent with 
the season, and the site landscape was almost the same as it was in the fall. Site $\mathrm{C} 2$ underwent a severe drought and lost canopy. In site A the fence of banana trees was cut, the land was cleared of biological debris, and no sand flies were captured in the chicken houses that were proximal to the pigsty (data not shown). The banana trees were significant places for the evaluation of population dynamics of Lu. intermedia complex species (Lu. neivai and Lu. intermedia) as was already noticed in Brazil (dos Santos et al. 2005, Lemos \& Lima 2005). On the other hand, the largest $L u$. neivai spring captures were obtained in the ecotone that was close to the recently built neighbourhood on the northern border. The sites sampled near these new houses showed an association of $L u$. neivai abundance with dense vegetation and shadows, and the differences between successive days and closely located sites, as occurred in the farm during autumn. In this neighbourhood the risk of transmission was centralized in the ecotone, but was also eventually in the houses during an exceptional phlebotomine population peak.

Oran is the most populated city within the area that has the highest incidence of ACL in Argentina. The local health system reported many cases that live in urban and peri-urban residences, and there are common perceptions of ACL urban transmission. On the other hand, the peridomestication and urbanization trends of cutaneous leishmaniases were proposed during the recent decades for many countries in order to explain the increase of ACL (Mott et al. 1990, Campbell-Lendrum et al. 2001, Desjeux 2001, Shaw 2007).

Landscape destruction was usually associated with leishmaniasis in the short time by the ephimerous interaction of man and the zoonotic sylvatic cycle (Ashford 2007), but also there are eventual medium term and long term effects as concentration of vectors/reservoirs in residual patches (hot spots), changes in the interaction with these patches (e.g., distribution of domestic animals), domestication of permissive vectors, and changes in the spatial distribution of shadow/humidity (Wassemberg et al. 2003, Shaw 2007, Volf \& Myskova 2007). Many of these changes both in the environment and peridomestic vector abundance were reported in ACL epidemic foci due to Lu. intermedia (Rangel \& Lainson 2003), the sibling species of Lu. neivai (Marcondes 1996, Andrade-Filho et al. 2007), and for Lu. neivai (Salomon et al. 2006). The risk due to landscape modifications and urbanization was also related with the dispersal pattern and colonization capacity of the species involved. In mark-release-recapture experiments in an ACL endemic rural focus $90 \%$ of the Lu neivai were recaptured up to $70 \mathrm{~m}$ from the release points, and $16 \%$ of the flies released in forest edge were caught in the peridomestic habitat (Casanova et al. 2005). Further, taking into account that $L u$. neivai in the same area already showed metapopulation patterns (Salomon et al. 2004) the little modified wooded area $3 \mathrm{~km}$ away to the East from site A $\left(500 \mathrm{~km}^{2}\right)$ could be a phlebotomine source population. Thus, $L u$. neivai metapopulation pattern, colonization potential, and survival in peridomestic residual habitats arise the question of urban ACL transmission.
In this study the spatial distribution of competent vector abundance in Oran city was described in order to understand the actual scenario of ACL spread in the highly modified urban environments and urban transmission probability. However, the risk of human- $L$. braziliensis vector effective contact in urban environments of the studied area during inter-epidemic periods is still associated with peri-urban wood patches, in the peridomesticsecondary vegetation ecotones, with a high abundance of $L u$. neivai despite the residence of the cases, as was reported for Lu. intermedia in Rio de Janeiro (Kawa \& Sabroza 2002). The peri-urban sand flies may belong to extinguishable local populations that are related to source populations from more modified habitats (Pulliam 1996) as the Eastern forests of Oran. Although, these vector populations could reach the city external neighbourhoods during vector exceptional population peaks-epidemic outbreaks, any spatial control or focal case-related control of phlebotomine inside the city will have dubious impact in the transmission at community level. On the other hand, changes in the environment at the micro-scale resulted in vector abundance fluctuations, indicating that the risk assessment of ACL transmission due to land use modifications in the hyper-endemic areas should be mandatory.

The distribution of phlebotomine around the "hot spots' also suggests that the risk of transmission is a narrow space-time associated probability that is related to physical, ecological and anthropic factors such as weather, relative humidity, quality of vegetation and shadow, and animal management. Therefore, small-scale local landscape heterogeneity should be taken into account by control programs that want to measure the actual risk with regular sand fly trapping in the so called 'representative' or 'sentinel' sites for surveillance, for case-focus delimitation, or for evaluation of anti-vectorial intervention.

\section{ACKNOWLEDGEMENTS}

To CENDIES-ANLIS and Coordinación de Vectores-Ministerio de Salud de la Nación, INSUE-Universidad Nacional de Tucumán, Coordinación de Vectores for their administrative and technical support. To Mario Scavuzzo and Marcelo Lamfri (CONAE) for providing the satellite image and Federico Vianconi (CNCV, Oran) for help with sand fly collections.

\section{REFERENCES}

Alexander B 2000. Sampling methods for phlebotomine sandflies. Med Vet Entomol 14: 109-122.

Andrade-Filho JD, Galati EA, Falcão AL 2007. Nyssomyia intermedia (Lutz \& Neiva, 1912) and Nyssomyia neivai (Pinto, 1926) (Diptera: Psychodidae: Phlebotominae) geographical distribution and epidemiological importance. Mem Inst Oswaldo Cruz 102: 481-487.

Ashford RW 2007. Disease as a stabilizing factor in the protection of landscape: the leishmaniases models. EcoHealth 4: 99-103.

Bejarano EE, Uribe S, Rojas W, Dario Velez I 2002. Phlebotomine sand flies (Diptera: Psychodidae) associated with the appearance of urban Leishmaniasis in the city of Sincelejo, Colombia. Mem Inst Oswaldo Cruz 97: 645-647.

Bernasconi VE 1930. Consideraciones sobre el censo de leishmaniosis. Rev Soc Pat Reg Norte 5: 590-602. 
Cabrera AL 1971. Fitogeografía de la República Argentina. Bol Soc Arg Bot 14: 1-50.

Campbell-Lendrum D, Dujardin JP, Martínez E, Feliciangeli MD, Pérez JE, Silans LN, Desjeux P 2001. Domestic and peridomestic transmission of American cutaneous leishmaniasis: changing epidemiological patterns present new control opportunities. Mem Inst Oswaldo Cruz 96: 159-162.

Casanova C, Costa AI, Natal D 2005. Dispersal pattern of the sand fly Lutzomyia neivai (Diptera: Psychodidae) in a cutaneous leishmaniasis endemic rural area in Southeastern Brazil. Mem Inst Oswaldo Cruz 100: 719-724.

Chaves LF, Añez N 2004. Species co-occurrence and feeding behavior in sand fly transmission of American cutaneous leishmaniasis in western Venezuela. Acta Trop 92: 219-224.

Cordoba-Lanus E, Lizarralde de Grosso M, Piñero JE, Valladares B, Salomon OD 2006. Natural infection of Lutzomyia neivai with Leishmania spp. in northwestern argentina. Acta Trop 98: 1-5.

Cordoba-Lanus E, Piñero JE, Gonzalez AC, Valladares B, de Grosso ML, Salomon OD 2005. Detection of Leishmania braziliensis in human paraffin-embedded tissues from Tucuman, Argentina by polymerase chain reaction. Mem Inst Oswaldo Cruz 100: 187-192.

Davies CR, Reithinger R, Campbell-Lendrum D, Feliciangeli MD, Borges R, Rodriguez N 2000. The epidemiology and control of leishmaniasis in Andean countries. Cad Saude Publica 16: 925-950.

de Pita-Pereira D, Alves CR, Souza MB, Brazil RP, Bertho AL, de Figueiredo Barbosa A, Britto CC 2005. Identification of naturally infected Lutzomyia intermedia and Lutzomyia migonei with Leishmania (Viannia) braziliensis in Rio de Janeiro (Brazil revealed by a PCR multiplex non-isotopic hybridisation assay. Trans R Soc Trop Med Hyg 99: 905-913.

Desjeux P 2001. The increase in risk factors for leishmaniasis worldwide. Trans $R$ Soc Trop Med Hyg 95: 239-243.

Dos Santos GP, Sanavria A, Marzochi MC, dos Santos EG, Silva VL, Pacheco RS, Mouta-Confort E, Espíndola CB, de Souza MB, Ponte CS, da Conceição NF, de Andrade MV 2005. Prevalência de infecção canina em áreas endêmicas de leishmaniose tegumentar americana do município de Paracambi, Estado do Rio de Janeiro, no período entre 1992 e 1993. Rev Soc Bras Med Trop 38: 161-166.

Galati EAB 2003. Classificação de Phlebotomine. In EF Rangel, R Lainson, Flebotomíneos do Brasil, Editora Fiocruz, Rio de Janeiro, p. 23-52.

Kawa H, Sabroza PC 2002. Espacialização da leishmaniose tegumentar na cidade do Rio de Janeiro. Cad Saude Publica 18: 853-865.

Lemos JC, Lima SC 2005. Leishmaniose tegumentar americana: flebotomíneos em área de transmissão no Município de Uberlândia, MG. Rev Soc Bras Med Trop 38: 22-26.

Leonardo FS, Rebêlo JM 2004. A periurbanização de Lutzomyia whitmani em área de foco de leishmaniose cutânea, no Estado do Maranhão. Brasil. Rev Soc Bras Med Trop 37: 282-284.

Marcondes CB 1996. A redescription of Lutzomyia (Nyssomyia) intermedia (Lutz \& Neiva, 1912), and resurrection of L. neivai
(Pinto, 1926) (Diptera, Psychodidae, Phlebotominae). Mem Inst Oswaldo Cruz 91: 457-462.

Massafera R, da Silva AM, Carvalho AP, dos Santos DR, Galati EA, Teodoro U 2005. Fauna de flebotomíneos do município de Bandeirantes, no Estado do Paraná. Rev Saude Publica 39: 571-577.

Mott KE, Desjeux P, Moncayo A, Ranque P, de Raadt P 1990. Parasitic diseases and urban development. Bull World Health Organ 68: 691-698.

Pulliam HR 1996. Sources and Sinks. In OE Rhodes, RK Chesser, MH Smith, Population Dynamics in Ecological Space and Time, University of Chicago Press, Chicago, p. 45-69.

Rangel EF, Lainson R 2003. Ecologia das leishmanioses. In EF Rangel, R Lainson, Flebotomíneos do Brasil, Editora Fiocruz, Rio de Janeiro, p. 291-310.

Salomon OD, Orellano PW, Quintana MG, Perez S, Sosa Estani S, Acardi S, Lamfri M 2006. Transmisión de la leishmaniasis tegumentaria en Argentina. Medicina (B Aires) 66: 211-219.

Salomon OD, Sosa Estani S, Canini L, Cordoba Lanus E 2001. Leishmaniosis tegumentaria en un área con niveles epidémicos de transmisión, Salta, Argentina, 1998. Medicina (B Aires) 61: 284-290.

Salomon OD, Wilson ML, Munstermann LE, Travi BL 2004. Spatial and temporal patterns of Phlebotominae sand flies (Diptera: Psychodidae) in a cutaneous Leishmaniaisis focus in Northern Argentina. J Med Entomol 41: 33-39.

Segura EL, Juan N, Piquin AL, Cuba Cuba CA, Abramo Orrego L, McMahon-Pratt D, Montamat EE, Momen H, Grimaldi Jr G 2000. Molecular and biologic characterization of Leishmania parasites implicated in an epidemic outbreak in northwestern Argentina. Parasitol Res 86: 504-508.

Shaw J 2007. The leishmaniases-survival and expansion in a changing world. Mem Inst Oswaldo Cruz 102: 541-547.

Sosa Estani S, Salomon OD 2002. Aspectos clínicos, epidemiológicos y entomológicos de la transmisión de la leishmaniosis en la República Argentina. SIIC Salud. Available from: http:/www. siicsalud.com/des/expertocompleto.php/20198.

Sosa Estani S, Segura EL, Salomon OD, Gomez A, Peralta M, Coutada V 2000. Tegumentary leishmaniasis in Northern Argentina: distribution of infection and disease, in three municipalities of Salta, 1990-1992. Rev Soc Bras Med Trop 33: 573-582.

Sudia WD, Chamberlain RW 1962. Battery operated light trap, an improved model. Mosquito News 22: 126-129.

Volf P, Myskova J 2007. Sand flies and Leishmania: specific versus permissive vectors. Trends Parasitol 23: 91-92.

Wassenberg G, Abramsky Z, Kotler BP, Ostfeld RS, Yarom I, Warburg A 2003. Anthropogenic disturbances enyhance occurrence of cutaneous leishmaniasis in Israel deserts: patterns and mechanisms. Ecol Appl 13: 868-881.

Young DG, Duncan MA 1994. Guide to the identification and geographic distribution of Lutzomyia sand flies in Mexico, the West Indies, Central and South America (Diptera: Psychodidae). Mem Am Entomol Inst 54: 1-881. 